\title{
A CONCEPÇÃO DE PROFESSORES SOBRE SEXUALIDADE
}

\author{
Maria José Dias de Freitas'; José Roberto da Silva Brêtas² \\ THE TEACHER'S CONCEPTION ON SEXUALITY \\ LA CONCEPCIÓN DE LOS MAESTROS ACERCA DE LA SEXUALIDAD
}

\begin{abstract}
Resumo: Trata-se de um estudo descritivo com abordagem qualitativa e produção dos dados por meio de Grupo Focal. Buscou-se conhecer as concepções e dificuldades de professoras de Creche, Educação Infantil e Ensino Fundamental I, sobre a sexualidade no ambiente escolar. A análise dos dados foi realizada mediante a análise de conteúdo temática, do tipo categorial, que produziu duas categorias temáticas. Os resultados apontaram dificuldades das professoras em relação à temática. A falta de conhecimento produz informações e crenças estereotipadas, representadas no cotidiano da escola em forma de preconceito e indiferença. O desconhecimento decorre de três fatores: formação deficiente sobre o tema, construções sócio-históricas e visão da sexualidade centrada no ponto de vista adulto. O estudo sinaliza questões importantes a serem incluídas na formação inicial e continuada de professores.
\end{abstract}

Palavras-chave: Educação Sexual. Escola. Formação de Professores. Gênero. Sexualidade.

Abstract: This is a descriptive study with a qualitative approach and data production through the Focus Group. It was sought to know the conceptions and difficulties of teachers of Kindergarten, Early Childhood Education and Primary Education I, about sexuality in the school environment. The analysis of the data was performed through the Thematic Content Analysis, of the categorical type, which produced two thematic categories. The results pointed out difficulties of the teachers in relation to the theme. The lack of knowledge produces stereotyped information and beliefs, represented in the daily life of the school in the form of prejudice and indifference. The lack of knowledge stems from three factors: deficient formation on the subject, socio-historical constructions and a view of sexuality centered on the adult point of view. The study points out important issues to be included in initial and continuing teacher training.

Keywords: Sex Education. School. Teacher training. Gender. Sexuality.

Resumen: Este es un estudio descriptivo con un abordaje cualitativo y producción de los datos a través de um Grupo Focal. Se buscó conocer las concepciones y dificultades de maestras de Guardería, Educación Infantil y Enseñanza Fundamental I, acerca de la sexualidad en el ambiente escolar. El análisis de los datos fue realizado através del análisis de contenido temático, del tipo categorial, que produjo dos categorías temáticas. Los resultados demostraron dificultades de las maestras con relación a la temática. La falta de conocimiento produce informaciones y creencias estereotipadas, representadas en el cotidiano de la escuela en forma de prejuicio e indiferencia. El desconocimiento se deriva de tres factores: la formación deficiente acerca del tema, las construcciones sociohistóricas y la visión de la sexualidade enfocada en un punto de vista adulto. El estudio señala cuestiones importantes a incluir en la formación inicial y continuada de los maestros.

Palabras clave: Educación Sexual. Escuela. Formación de maestros. Género. Sexualidad.

\footnotetext{
' Pedagoga. Professora da Universidade Paulista (UNIP). Doutora em Ciências pela Universidade Federal de São Paulo (Unifesp). E-mail: mjddfreitas@gmail.com

2 Psicólogo. Professor orientador do Programa de Pós-Graduação em Educação e Saúde na Infância e na Adolescência, da Universidade Federal de São Paulo (Unifesp). Especialista em Sexualidade Humana na área de Educação Sexual pela Sociedade Brasileira de Estudos em Sexualidade Humana (SBRASH). E-mail: bretas.roberto@unifesp.br
} 


\section{Introdução}

A temática da educação em sexualidade não tem sido pauta comum nas esferas governamentais e sociais. Houve um período histórico em que existia a preocupação em fomentar ações para minimizar agravos e aumentar o acesso ao conhecimento e às informações. Um dos exemplos foram cursos ofertados aos professores pelo poder público que envolvia gênero e diversidade na escola, que formou professores do Ensino Fundamental II, de $5^{\mathrm{a}}$ a $8^{\mathrm{a}}$ séries (HEILBORN; ROHDEN, 2009). O Ministério da Educação e Cultura (MEC), por meio da Secretaria de Educação Continuada, Alfabetização e Diversidade (SECAD), também desenvolveu documentos para formar professores do Ensino Médio, o Kit Escola sem Homofobia (HENRIQUES et al., 2007).

Dessa forma, observou-se uma estagnação na área, no que se refere à formação de professores e professoras, desde a publicação dos documentos acima referidos. De acordo com Mello, Avelar e Maroja (2012), ao analisar a efetividade dos planos, programas e conferências produzidos e promovidos pelo governo federal em relação às políticas públicas para a população de Lésbicas, Gays, Bissexuais, Travestis, Transexuais ou Transgêneros (LGBT), percebem-se retrocesso e estagnação na implantação de ações decorrentes de tais documentos: - Programa Brasil sem Homofobia, os Anais da I Conferência Nacional LGBT, o Plano Nacional de Promoção da Cidadania e Direitos Humanos LGBT e o Programa Nacional de Direitos Humanos. Entre os documentos que os autores analisaram, está o Brasil sem Homofobia (2004), programa que, em sua gênese, tem como foco fomentar e apoiar a formação inicial e continuada de professores na área da sexualidade (CONSELHO NACIONAL DE COMBATE À DISCRIMINAÇÃO, 2004). No entanto, a partir da análise crítica dos documentos, levando em conta entrevistas com gestores(as) de diferentes esferas governamentais municipais, estaduais e federais e com a sociedade civil, Mello, Avelar e Maroja (20I2) constataram que, apesar da "capilarização" lenta em alguns órgãos, como a Secretaria de Direitos Humanos (SHD), o Programa nunca assumiu o status de:

[...] decreto, resolução, portaria ou qualquer outro ato normativo secundário que, lhe atribuísse maior formalização e materialidade no universo das iniciativas do governo federal (MELLO; AVELAR; MAROJA, 2012, p. 296)

A partir das constatações acima, nota-se que pouco avançamos em termos de ações efetivas ou grandes materializações das ações objetivadas a partir do Brasil sem Homofobia. Além disso, é visível que precisamos superar as resistências "[...] homofóbicas institucionais, a inexperiência na execução de políticas transversais e Inter setoriais relativas a gênero e direitos sexuais e as carências orçamentárias" (MELLO; AVELAR; MAROJA, 20I2).

O Brasil é signatário dos Princípios de Yogyakarta (2007), em que se comprometeu a implantar ações em prol dos direitos humanos assegurando uma educação que respeite as diversas orientações sexuais e identidades de gênero. Em 2013 foi instituída a Lei $n^{\circ} 12.852$, - Estatuto da Juventude, que, na secção IV no Art. I8, item III, cita como premissa a formação dos profissionais de educação em relação aos temas de "[...] orientação sexual, de gênero e de violência doméstica e sexual". Apesar dessa lei, acompanhamos uma lacuna na formação docente nesse sentido.

Recentemente a Unesco (20I4), após quase três anos de discussões junto a especialistas brasileiros sobre a adaptação de um documento internacional para o nosso cenário, finalizou as adequações de um instrumento que abarca a faixa etária de entre 5 e 18 anos, com perfil bastante adequado e de qualidade para o contexto brasileiro. Os tópicos e objetivos de aprendizagem são apresentados em níveis, sendo que cada nível corresponde a uma faixa etária.

Observamos que as políticas públicas de formação ainda não contemplam professores que atuam em Creche, na Educação Infantil e no Ensino Fundamental anos iniciais, de $\mathrm{I}^{\mathrm{a}}$ a $5^{\mathrm{a}}$ séries. $\mathrm{O}$ documento da Unesco (2014) sinaliza para o desenvolvimento de ações na faixa etária nível I, de 5 a 8 anos, e nível II, de 9 a 12 anos, idade que equivale aos anos finais da Educação Infantil e Ensino Fundamental anos Iniciais. Sendo que a faixa etária pertencente à Creche e às outras etapas da Educação Infantil, isto é, de 0 a 4 anos e II meses, não foi contemplada.

Diante do exposto, apresentamos os desafios enfrentados por professoras que atuam nessa etapa da escolarização em situações cotidianas envolvendo o tema sexualidade.

A partir do contexto apresentado, o objetivo deste estudo foi conhecer as concepções e dificuldades de professoras de Creche, Educação Infantil e Ensino Fundamental I, sobre a sexualidade no ambiente escolar.

\section{Método}

Trata-se de um estudo de abordagem qualitativa, do tipo exploratório-descritivo. Segundo Gil (2006), o estudo descritivo retrata as características de determinada população ou fatos e fenômenos de determinada realidade; promove um delineamento da realidade uma vez que esta descreve, registra, analisa e interpreta a natureza ou processos dos fenômenos.

Em relação aos procedimentos éticos, o projeto deste estudo foi submetido à Plataforma Brasil/Comitê de Ética da Universidade Federal de São Paulo (Unifesp) e aprovado com protocolo $n^{\circ} 141209$, atendendo todos 
os procedimentos metodológicos norteados pelos padrões estabelecidos pela Resolução $n^{\circ} 466 / 12$, que trata das normas de pesquisa envolvendo seres humanos (CONSELHO NACIONAL DE SAÚDE, 20I3). É importante ressaltar que o termo de assentimento foi devidamente esclarecido e assinado pelas participantes do estudo.

Para tanto, utilizamos uma amostra intencional, pela qual as participantes foram selecionadas para refletir a variedade dos sujeitos do estudo. $O$ grupo foi composto a partir de alguns critérios associados às metas da pesquisa como: a heterogeneidade das participantes (professoras de Creche, Educação Infantil e Ensino Fundamental I), porém com suficiente variação entre elas para que aparecessem opiniões diferentes ou divergentes (GATTI, 2005; KITZINGER, 2009).

Nesse contexto, integrou o estudo 15 professoras com idades entre 26 e 44 anos, que se voluntariaram para participar do estudo após convite feito à direção de uma escola pública situada na zona sul do município de São Paulo. Das 15 professoras, 13 tinham curso superior completo em Pedagogia, uma estava cursando Pedagogia e outra tinha formação em Magistério (Ensino Médio). Em relação ao local de trabalho, seis professoras atuavam na Creche, na Educação Infantil e tinham escolaridade superior em Pedagogia e as nove professoras restantes, atuavam no ensino fundamental anos iniciais, sendo que uma tinha o Magistério.

Para a geração de dados, optou-se pela técnica de grupo focal. Nesse contexto, foram desenvolvidos dois grupos focais distintos, um de professoras da Creche e da Educação Infantil e o outro de professoras de Ensino Fundamental I, a partir de oito sessões grupais. A composição do grupo focal foi pautada na literatura, em que se destacaram duas figuras fundamentais: o moderador e o observador. Ao moderador coube a função de apresentar questionamentos condizentes com os objetivos do estudo, fomentando a participação ativa dos sujeitos na discussão; já o observador teve o papel de assimilar as informações não verbais manifestadas pelos participantes, anotando-as em diário de campo (GATTI, 2005).

As sessões em grupo ocorreram nas dependências da escola e apresentaram duração média de uma hora e meia. Foram guiadas por um roteiro para nortear as discussões, organizado a partir de momentos-chave: abertura (apresentação, informações e contrato de horário); debate; síntese; e encerramento. $\bigcirc$ registro das sessões foi realizado através do recurso de gravação (áudio), visando uma transcrição de dados fidedigna. As perguntas norteadoras do estudo foram "O que entende por sexualidade?"; "Como você percebe no ambiente escolar as manifestações da sexualidade da criança?".

Para o tratamento dos dados, utilizou-se a análise de conteúdo temática, a qual foi organizada em três fases: a pré-análise, que consistiu na escolha do material a ser analisado e a retomada dos objetivos iniciais da pesquisa, leitura flutuante e constituição do corpus (aplicação de normas qualitativas, como a exaustividade, representatividade e homogeneidade); a exploração do material, que foi classificado por núcleos de compreensão do texto; tratamento dos resultados obtidos e interpretação (MINAYO, 2010).

\section{Resultados e discussão}

As discussões oriundas da análise das narrativas das participantes do estudo foram agregadas em duas categorias temáticas: (I) a concepção de sexualidade; (2) percepção da sexualidade no ambiente escolar.

\section{Categoria I - A concepção de sexualidade}

Nas trocas de fraldas, assim como nas salas de aulas, aparecem algumas incertezas, tabus, preconceitos, estigmas e estereótipos. No que se refere a conceitos, constatamos divergências entre as definições de sexo e sexualidade, bem como observamos o olhar "erotizado" e "genitalizado" do adulto frente à sexualidade infantil.

No entanto, antes de iniciar as considerações, precisamos deixar claro alguns conceitos importantes para a educação. $\mathrm{Na}$ formação docente temos conteúdos sobre desenvolvimento da criança, do adolescente e do adulto. Apesar de haver algumas lacunas na formação docente, existem autores que são imprescindíveis na formação e possibilitam aos educadores(as) compreender aspectos importantes da aprendizagem e do desenvolvimento humano.

Do mesmo modo que exigimos dos professores e das professoras um conhecimento acerca de definições do que é sexo e sexualidade - e da escola um trabalho com a temática de educação em sexualidade -, percebemos que as instituições que formam esse profissional não abarcam essa temática em seus currículos.

Unbehaum, Cavasin e Gava (2010) citam que existe um vasto campo de estudos e análises de legislações e reformas federais no âmbito da educação, porém - campo de estudos se restringe significativamente quando se quer uma análise mais específica sobre os conteúdos que compõem a formação docente, o currículo dos cursos de pedagogia e licenciaturas no que se refere a temas como educação sexual, sexualidade, relações de gênero. Corroborando com as autoras, percebemos que nos últimos cinco anos, nas esferas públicas, pouco se tem realizado efetivamente em relação às questões de implantação de políticas de formação sobre o tema da sexualidade.

A partir dos encontros do grupo estudado, foi constatada a dificuldade das professoras em lidar com situações pontuais em sala de aula envolvendo o assunto. 
Por exemplo, na Creche, quando o corpo da criança é manuseado na atenção de suas necessidades básicas; na Educação Infantil, quando as crianças começam a perceber diferenças no corpo de meninos e meninas e de homens e mulheres; nas conversas relacionadas ao desenvolvimento do corpo que ocorrem entre alunos e alunas do Ensino Fundamental anos iniciais. As próprias professoras afirmam ter dificuldades e desconhecimento para lidar com as questões da educação em sexualidade - seja por sua formação não abarcar esse tipo de conteúdo ou pelo próprio currículo que não possibilitou esse aprendizado. A maioria foi enfática em declarar que nunca teve um conteúdo que as capacitasse, sendo que apenas uma professora afirmou que era necessário "ter sexo bom em casa, ser bem resolvida, assim você seria bem resolvida com as crianças. [...] se você é bem resolvida na sexualidade em casa com seu marido você vai saber lidar" (Professora 8 , EF). No entanto, o que interessa não é a vida privada do docente e sim a formação do docente para lidar com temas que explore essa temática.

Às vezes, no sistema escolar, falta uma visão mais ampla de como é o universo da criança. Segundo Freire (20I I), deve-se buscar alternativas para que o ensino se dê não apenas de maneira rígida, que não se obrigue os alunos e as alunas a uma atitude passiva de silêncio e imobilidade, mas sim proporcionar que todas as situações de aprendizagem sejam interessantes para a criança. Queremos uma sociedade livre, no entanto restringimos a liberdade das crianças. Nessa parte, a escola tem um papel fundamental: a de não restringir o movimento corporal das crianças e proporcionar uma integração entre o corpo e a mente.

$\mathrm{Na}$ escola, mas não somente nela, há um esforço na manutenção de uma ordem social que dá ênfase a um comportamento "pré-fabricado" (BERNARDI, 1985), isto é, a maior parte da vida aprendemos que a "[...] renúncia é meritória e o prazer é culpável, que a resignação é obrigatória e que a aprovação social e a segurança são bens mais desejáveis [...]" (BERNARDI, 1985, p. 27). Logo, qualquer comportamento ou manifestação que envolva o corpo, mais especificamente a sexualidade, é um problema na escola.

Nessa perspectiva do corpo em movimento e das questões levantadas pelas professoras, indagamos o que elas pensavam da sexualidade, assim como:

Sexualidade seria assim, eu acho tudo o masculino e o feminino, como lidar com o próximo, o respeito com o corpo, a relação que você tem com você, como você se vê como pessoa, como mulher, você passa a enxergar a pessoa como homem, então eu imagino assim. (Professora 3EF - 35 anos, feminino, psicopedagoga, função professora do $I^{a}$ ano EF anos iniciais-crianças de 6 e 7 anos)
A sexualidade eu percebo nos meus filhos uma criança de dois anos e um de 12 anos. $O$ pequeno esses dias eu fui tomar banho e ele entrou no banheiro e falou: mamãe não tem um "piu-piu", não a mamãe não tem, não tem e baixou a calça é diferente do meu. (Professora 4 El - 33 anos, feminino, ensino superior completo, função professora maternal I - crianças de 2 anos e 3 meses até 3 anos)

A definição de sexualidade se confunde com a de sexo, diferença anatômica entre masculino e feminino, mesclando-se com questões morais e subjetivas. Também são citados respeito e desejo como definições de sexualidade. Confunde-se o conceito de sexualidade com questões apenas do desenvolvimento ou relacionada ao sexo biológico, no entanto, fica claro que as subjetividades dessas professoras são únicas e carregadas de significados. Observamos também que há a percepção de sentimentos de afeto e carinho, pontos fundamentais quando se fala em sexualidade.

Bernardi (1985) orienta para que façamos um exercício de "reeducação sexual" frente à "deseducação sexual" a que estamos continuamente submetidos. No entanto, sabemos que essa ruptura não é fácil. Por isso, propomos uma inflexão dos padrões com os quais fomos socializados ao que se refere à sexualidade e à educação em sexualidade. Nesse sentido, Bozon (2004) afirma que a escola é um local privilegiado para tratar questões da educação em sexualidade e justifica que, nesse ambiente, é possível despersonalizar a "transmissão entre as gerações". Mas com uma condição: para que isso aconteça, faz-se necessário que os currículos da pedagogia e das licenciaturas abarquem a temática da educação em sexualidade. A partir desse trabalho educativo, de criar uma visão mais positiva em relação às questões do corpo e da sexualidade, será possível realmente despersonalizar os conceitos ultrapassados e conservadores.

A partir desse raciocínio a sexualidade é muito mais ampla que a ideia apresentada a seguir:

Sexualidade é descobrir quem você é, [...] ele tem 'torneirinha' e não tem aquela coisa de se descobrir? Descobrir que tem um corpo diferente da coleguinha, descobrir como respeitar esse corpo, descobrir o que tem de diferente, o que me dá 'prazer' o que não dá. (Professora 7 El/EF anos iniciais- 36 anos, feminino, estudou arquitetura e urbanismo, licenciatura plena em artes e pós em história da arte, função professora de artes do maternal ao $\mathrm{EF}$ anos iniciais MII; JF: JII; I ${ }^{\mathrm{a}} ; 2^{\mathrm{a}} ; 3^{\mathrm{a}}, 4^{\mathrm{a}}$ e $5^{\circ}$ )

$\mathrm{Na}$ educação em sexualidade da criança é comum apontar que meninos e meninas são diferentes. Segundo Furlani (2010), as diferenças enfatizadas estão na noção de que os "meninos têm pênis" e as meninas tem "vagina", sendo que o certo seria "vulva". Assim, a sexualidade fica resumida a diferença entre os órgãos genitais, o que acaba por reforçar estereótipos e uma concepção 
“binária masculino/feminino" (LOURO, 200I) e que acaba por determinar também quais as atividades e brincadeiras que são permitidas a meninos e meninas.

No entanto, segundo Auad (2006), as representações sobre o masculino e o feminino, além do sexo dos sujeitos, são utilizadas para organizar as práticas escolares. São, contudo, silenciados nos discursos. Dessa forma, não se pensa sobre como a utilização desses elementos na organização do trabalho na escola pode promover situações de desigualdade.

Uma professora comentou sobre o comportamento de um menino de seis anos, como segue:

Eu percebi na sala que um estava passando a mão no outro, 'ah prô ele fica me pegando'. Conversei com o professor de educação fisica ele disse que isso vem desde o ano passado esse mesmo menino de seis anos pega no outro menino, fica segurando o menino, passa a mão no menino. Então eu não sei se é curiosidade ou é do jardim como surgiu isso dele passar a mão nos amigos. (Professora 3 EF - 35 anos, feminino, psicopedagoga, função professora de crianças de 6 e 7 anos)

Constatamos na narrativa que as expressões entre meninos, de se tocar ou de carinho, são traduzidas com certa desconfiança por parte das professoras. Assim, a camaradagem entre os meninos precisa ser cautelosa, caso contrário sofre interpretações dúbias. Para eles, são autorizados apenas comportamentos e gestos que não se afastem do padrão heteronormativo definido como adequado para um "macho" (LOURO, 200I). O modelo hegemônico, ou seja, "normal", de masculinidade é tão predominante que muitos creem que as características e condutas associadas ao mesmo sejam "naturais" (CONNELL, 1995). Connell (1995) alerta que em um mesmo lugar podem existir múltiplos tipos de masculinidades, pois, se o gênero é um produto histórico, então ele está aberto a mudanças históricas.

O constructo social de que meninos são fortes, corajosos e durões e de que meninas são delicadas, meigas e carinhosas é uma concepção que sinaliza apenas um tipo de masculinidade e um tipo de feminilidade. Essa visão única acaba por privar as crianças de novas experiências corporais e afetivas e momentos importantes de convivência.

Segundo Auad (2006), as diferenças entre meninas e meninos certamente não são naturais. Meninas que aparentam meiguice ou meninos que falam aos gritos são resultantes do modo como as relações de gênero foram construídas na nossa sociedade ao longo do tempo.

Finco (2007) afirma que hoje ainda disciplinamos os corpos das crianças quando as colocamos em salas de Educação Infantil que imitam modelos convencionais de outras etapas escolares, com mesas e cadeiras, o que acaba por reduzir a mobilidade e o brincar, escolarizando dessa forma também os próprios corpos e o próprio brincar.

Para modificar essa situação e para que aconteçam as mudanças de entendimento quanto aos padrões de masculinidade, é preciso perceber como foram moldados os padrões e buscar remoldá-los. Nesse sentido, é premissa romper com os discursos que definem sentimentos e ações como condutas específicas para homens, bem como romper com a tendência de adotar apenas uma forma de masculinidade para definir todas as outras. Logo, faz-se necessário extinguir o pensamento de que quando um indivíduo nasce já está impressa a sua masculinidade e não há o que se apropriar de novo. A masculinidade ocorre tanto como um projeto individual quanto coletivo, sendo algo que está em constante transformação. O processo de construção também é válido para as feminilidades.

Connell (1995) indica que a forma mais efetiva de educação sexual é "aprender a ser o sexo oposto", isto é, movimentar-se entre as diferentes posições de gênero na cultura, colocar-se na condição do outro. Faz-se necessário desenvolver um trabalho educacional com os grupos sociais, para que seja entendido o que é a masculinidade e a feminilidade para essa comunidade, tornando possível um debate que permita a reflexão sobre a existência de outras possibilidades de ser homem e de ser mulher.

Outras professoras se aproximam e se afastam do conceito de sexualidade quando referem que:

Sexualidade na criança quando é pequena, por exemplo, os nossos de zero a seis anos ainda estão explorando e ela não tem consciência muito do que ela pode ou não. Não tem a 'malícia' ainda. (Professora 2 EF- $4 \mathrm{I}$ anos, feminino, pedagoga, função orientadora pedagógica e professora EF anos iniciais).

A sexualidade começa na formação da criança e a partir daí vai desenvolvendo porque a criança ao 'mamar', ao 'sugar' ele já sente o 'prazer'. Então eu acho que a sexualidade é o "prazer" e aí vai desenvolvendo. (Professora 4 El - 33 anos, feminino, Ensino superior completo, função professora maternal I - crianças de 2 anos e 3 meses até 3 anos).

Sexualidade eu acho que é tudo que envolve prazer, tanto na fase da criança quanto no adulto é busca do prazer, uma troca no caso. (Professora 10 Creche/El- 26 anos, feminino, pedagoga, função professora educação infantil Berçário II $\mathrm{B}$ crianças de $\mathrm{I}$ ano e 8 meses até 2 anos).

Eu vejo a sexualidade como as etapas do desenvolvimento, as fases na infância, os meus alunos de nove anos, as meninas estão preparando o corpo já para menstruar [...] os meninos você também percebe. Então essa sexualidade acompanha desde o bebezinho até a fase adulta, a velhice eu acho que são as fases da vida relacionadas ao corpo. (Professora 6 
EF I- 36 anos, feminino, pedagoga, função professora EF anos iniciais).

Aqui observamos, no relato das professoras, a amamentação como uma das fontes de prazer primária do bebê, a alimentação. $O$ sugar é o momento em que inicialmente o bebê suga o seio materno para saciar a sua fome, sentindo saciedade passa a repetir esse gesto de sucção a fim de ter as mesmas sensações agradáveis.

Uma criança deve ser autônoma e independente, no entanto não deve ser sozinha. Necessita de um adulto que assuma o espaço de educador. Nesse contexto, não podemos deixar vago o espaço onde a criança trata de descobrir a "chave do seu desejo" (MILLOT, I987). Portanto, devemos qualificar as nossas ações cotidianas e buscar responder às indagações das crianças acompanhando o seu raciocínio, de acordo com a faixa etária, o que amplia sobremaneira a qualidade de vida das crianças.

Nesse sentido, a fragilidade de conhecimento de uma professora acerca do desenvolvimento da criança fica visível na representação que segue:

Tenho um aluno que começou a se 'manifestar', da sexualidade do 'prazer'. Ele começou a 'aflorar'. O menino tem um ano e cinco meses, ele estava em com o brinquedo João Bobo e a mãe o pegou abraçando o brinquedo. Ele estava excitado ele estava alegrinho, com o pênis ereto. [...] o menino agarrava o 'João bobo' e ficava puxando esfregando e a mãe dizia: é só por trás. A mãe tirava o "João bobo" e colocava na frente ele virava e queria só atrás. Ela tirava, ele virava, ela começou a ficar nervosa e tirou o brinquedo. E o pai disse: ele é homem faz assim mesmo é homem tem que fazer. E a mãe nervosa, mas não é normal isso parecia um 'cachorrinho no cio' ele pegava por trás ela pegava e colocava na frente ele ia atrás. (Professora 10 Creche - 26 anos, feminino, pedagoga, função professora educação infantil Berçário II B crianças de I ano e 8 meses até 2 anos)

A complexidade desse relato nos apresenta uma narrativa do adulto frente à sexualidade infantil. Constatamos na versão dos pais sentimentos carregados de conotações erotizadas, isto é, com cunho sexual que não condiz com a realidade da criança. Nessa faixa etária, de I ano e 5 meses, a criança alcançou uma autonomia relativa, já caminha e articula algumas palavras. Nessa perspectiva, a criança estava brincando com o boneco "João Bobo". Não havia a intenção atribuída pelos adultos. Precisamos partir do ponto de vista da criança, compreender a lógica dela e não lhe impor o referencial do adulto, pois compete ao adulto compreender a criança e não o contrário.

Ressaltamos aqui não apenas a questão da professora em mediar determinada situação, mas enfatizo a questão das Instituições de Ensino Superior (IES) que formam diariamente uma centena de professores e continuam insensíveis às demandas existentes dentro da escola.
Unbehaum e Cavasin (2012) realizaram um levantamento nas homepages de universidades nacionais nos currículos e ementas de 2000 cursos de Pedagogia para saber se havia ofertas de disciplinas na temática de gênero e sexualidade. Para isso utilizaram como descritores: sexualidade, educação sexual, relações de gênero, diversidade sexual, HIV/AIDS, prevenção, corpo e corporeidade e constataram que apenas $4 \mathrm{I}$ universidades continham alguma referência ao conjunto de palavras-chave. A grande maioria oferece disciplinas como optativas, isto é, o tema não faz parte das disciplinas obrigatórias. Isso nos leva a refletir acerca das condições em que é formado(a) esse(a) professor(a) e quais conteúdos são considerados imprescindíveis para ser um(a) bom/boa profissional.

A noção de sexualidade manifestada pelas professoras é apresentada desde uma descoberta ligada ao desenvolvimento até concepções ligadas a características físicas do corpo, como destacado:

Sexualidade é a descoberta do corpo, assim a curiosidade em descobrir o outro. (Professora 8 EF anos iniciais - 44 anos, feminino, superior completo pedagoga, função professora)

Sexualidade são as fases do cuidado do corpo. Tem a fase que a criança não gosta de cuidar do corpo. Não gosta de tomar banho. (Professora 9 EF anos iniciais - 30 anos, feminino, pedagogia superior, função professora)

A sexualidade é apresentada também como um atributo físico e biológico que pode ser manifestado por ações e comportamentos.

Sexualidade é a vaidade das meninas. (Professora 9 EF - 30 anos, feminino, pedagoga, função professora anos iniciais)

Sexualidade são intimidades, os hormônios, a sensualidade. Por exemplo, a minha filha de seis anos, ela quer colocar calça apertada topzinho e assim na sala dela também os meninos ficam encantados. Outro dia teve uma festa de aniversário dela, aí a professora falou assim: olha a cara dos meninos de boca aberta'. E aí ela começou a fazer perguntas para mim que os meninos queriam dar um beijo nela, eu falei que não, se fosse no rosto tudo bem, mas se fosse na boca não podia por ' $n$ ' fatores. Porque podia passar cárie, pode dá bichinho e falei que você não está na fase ainda. Sexualidade é tudo que envolve o corpo de uma forma mais íntima, a gente se conhecer e não ter vergonha. Sexualidade é maturidade, mudança, assim as mudanças do corpo das meninas e dos meninos e eles começam a mudar o pensamento. (Professora 4 El - 33 anos, feminino, ensino superior completo, função professora maternal I - crianças de 2 anos e 3 meses até 3 anos)

$\mathrm{Na}$ narrativa das professoras confirma-se novamente o conceito da Organização Mundial da Saúde (OMS), de 2002, sobre a sexualidade como um aspecto central do ser humano durante toda a vida e que abrange 
não apenas o sexo, mas a identidade de gênero, os papéis, a orientação sexual, o erotismo, o prazer, a intimidade e a reprodução.

Aparecem nos relatos ainda certezas e incertezas a respeito de a sexualidade pertencer apenas aos adolescentes e aos adultos, excluindo a criança, como se houvesse um aprendizado da sexualidade. A sexualidade nasce e morre conosco. Ela é "[...] experimentada e expressada em pensamentos, fantasias, desejos, crenças, atitudes, valores, comportamentos, práticas, desempenho de papéis e relacionamentos" (ORGANIZAÇÃO MUNDIAL DA SAÚDE, 2002). Embora a sexualidade possa incluir todas estas dimensões, "nem todas são sempre experienciadas ou expressadas" (ORGANIZAÇÃO MUNDIAL DA SAÚDE, 2002).

A sexualidade como foi apresentada pela OMS (2002) é influenciada pela interação de fatores "biológicos, psicológicos, sociais, econômicos, políticos, culturais, éticos, legais, históricos, religiosos e espirituais". Outro fator apresentado pelas professoras nos leva a crer que existe um conflito entre os conceitos sexualidade, sexo, sensualidade, erotismo e pornografia, bem como em relação ao significado apresentado de uso, de exploração do corpo quando afirma a utilidade "benéfica ou não" disso, como segue:

A sensualidade está mais envolvida para os jovens adolescentes é a sensualidade - sexualidade ela está mais para os adolescentes para a vida adulta. Com a criança eu acho que isso não acontece de uma forma consciente até porque eles estão ainda em descoberta. Mas com o adulto é a exploração do próprio corpo, de uma forma benéfica ou não. (Professora 2 El - 33 anos, feminino, pedagoga com habilitação em Educação Infantil, função orientação pedagógica da Educ. Infantil.)

Observamos claramente uma confusão de conceitos. Brêtas (20I I) afirma que a "sensualidade é o erótico". Ela nos permite "fantasiar". Pode até se referir ao "[...] ato sexual, mas sempre de uma forma indireta". A sexualidade é um aspecto central do ser humano durante toda a vida, abrange todas as faixas etárias e uma gama de atributos já mencionados. $O$ sexo é definido como a diferença biológica entre homens e mulheres, ou $o$ ato sexual em si.

No entanto o conceito de erótico é subjetivo a cada sociedade, de acordo com o tempo histórico haverá uma reação diferente a um mesmo estímulo. Picazio (1999) exemplifica o carnaval, quando algumas atitudes são aceitas, mulheres e homens com pouca ou sem roupa, brilhos e maquiagens extravagantes, porém em outras épocas do ano não são.

Assim, o que consideramos erótico e até mesmo pornográfico em uma determinada época ou sociedade pode se transformar. Em 1930 um beijo era considerado pornográfico. Na década de 1950, passou a ser considerado erótico. Hoje, passa despercebido. Já o pornográfico é geralmente vulgar, pode ofender ou chocar, porém o erótico é sensual, estimula a sexualidade e é atraente (PICAZIO, 1999).

A perspectiva apresentada de corpo como utensílio, que pode ser usado e até explorado de maneira "benéfica ou não", está carregada de valores subjetivos e até mesmo estereotipados que acabam por perpetuar alguns conceitos como o apresentado acima. Nesse sentido, Louro (2000) afirma que os corpos ganham sentido socialmente, são significados pela cultura e, continuamente, por ela alterados. Nessa perspectiva, o corpo recebe a noção de fazer uso benéfico, ou seja, do permitido, e a maleficência como o não consentido ou o socialmente não aceito. Podemos inferir que existe um padrão de comportamento socialmente aceito e que a forma como o indivíduo utilizar o seu corpo estará dentro ou fora dos padrões preestabelecidos e previamente ditos.

Uma das professoras da Educação Infantil apresentou sua explicação do que era sexualidade, como representado:

Sexualidade ela vem de vários parâmetros, a sexualidade que a pessoa leva para a criança, a sexualidade que a criança se descobre e a sexualidade de junção carnal. Olhar com desejo, com prazer, o olhar da gente do ato sexual, de mostrar, nossa como está bonita, gostosa de prazer. (Professora 7 El - 34 anos, feminino, pedagoga, função professora do Berçário idade de I ano e 4 meses até 2 anos e 4 meses)

Solicitei que explicasse mais o conceito de sexualidade por ela apresentado. Ela afirmou que no adulto é "junção carnal", isto é o "ato sexual", e que na criança é a "busca dela em conhecer o corpo". Afirmou que é o adulto que leva a sexualidade até a criança quando "passa um batom na criança e tenta fazer a criança sexy". Essa afirmação provocou um intenso debate durante o grupo focal entre as participantes, entre o aceitável, o inaceitável e o conflito que sinaliza a contradição do discurso.

Felipe (2010) afirma que o acesso infantil a informações do mundo adulto proporciona uma modificação drástica nas vivências das crianças. Ressalta que há um investimento maciço em montar uma identidade feminina, esculpida, fabricada enfim produzida que serve "[...] tanto para mulheres adultas quanto para meninas [...]" (FELIPE, 2010, p. 55).

A erotização dos corpos de crianças e adolescentes que vem ocorrendo na contemporaneidade é um fator importante. No entanto, percebemos que a posição das professoras frente à sexualidade infantil, a conotação que essa pessoa adulta atribui ao comportamento da criança acerca do corpo, bem como a influência dessa percepção sobre o desenvolvimento integral de crianças 
e adolescentes acaba por determinar uma visão estereotipada das mesmas.

Não podemos nos afastar de questões que são próprias da criança. $O$ fato de propiciar que ela experimente usar o batom ou roupas diferentes não necessariamente significa que se queira deixá-las sedutoras.

Proença (2004) enfatiza que a criança brinca, exercita a imaginação, cria e dá vazão à fantasia, pois, enquanto ser simbólico vivencia o mundo mágico do faz de conta e, brincando, internaliza e expressa práticas culturais que observou no mundo real que a cerca. A imitação do outro é a forma por meio da qual ela aprende, ao conhecer e se apropriar inicialmente do próprio corpo e, mais tarde, do mundo das ideias.

\section{Categoria 2 - A percepção da sexualidade no ambiente escolar}

A percepção da sexualidade no ambiente escolar pode ser contextualizada por uma professora que relatou sobre as "cabaninhas de beijar", explicou que as crianças vão para baixo das mesas para ficar trocando beijos. Outra contou-nos que ficou surpresa com o relato de uma criança de 7 anos:

Na minha sala tem uma aluna de sete anos quieta, calma, tranquila mesmo. Em conversa de 'roda' ela não tinha chegado ainda. (Um aluno falou):

- ah prô fulano beija cicrana.

- beijo? Por quê? (professora)

- porque gosta muito dela... (aluno)

Daí eu continuei na 'roda de conversa'...

- prô beijou na boca fulano, ciclano, beltrano quatro amigos daí todo mundo ficava atrás dela para abraçar ela. (aluno)

- E a prô? A prô não conseguia segurar eles. (professora)

Aproveitei a conversa da roda e disse olha lembra que eu falei que tem brincadeira que não dá certo que o pai fica bravo. O pai dessa menina com certeza vai ficar bravo. E bem na hora a mãe entrega a criança. Prô eu preciso falar com você tá? Eu já sei estão me falando. A mãe relatou que a menina falou, mas eu não beijei na boca, foi na língua. $O$ pai quase infartou, conversou que não queria isso que não dava certo que ela era muito nova, tinha tempo para namorar. Daí chegou no outro dia na sala e disse:

- ai prô fulano beijou. (aluna)

Eu disse beijou de novo você?? Vou mandar o seu pai falar com ele. Daí o menino disse:

- 'ela pede, eu peço e ela me beija, eu que pedi, mas a culpa é dela'.

É dela a culpa porque ela beijou ou é sua porque você pediu o beijo? Daí ele disse:

- mas ela quis beijar. Mas se o pai dela vier aqui? Quem vai conversar com o pai dela? Ela ou você? Daí ele ficou quieto. Isso passou. (Professora 3 EF-35 anos, feminino, psicopedagoga, função professora de crianças de 6 e 7 anos)

Geralmente os(as) professores(as) fazem uma "roda" com os alunos e alunas sentados/as em círculo no chão para conversar e contar as novidades. Essa atividade é muito bem aceita pelas crianças, é o momento em que a professora pode se aproximar e conhecer mais a realidade dos alunos e das alunas. Trata-se de um momento para conversar sobre assuntos diversos, acoIher as diferentes opiniões, bem como possibilitar o diálogo e a reflexão de vários temas.

As crianças fantasiam e se apropriam das realidades que vivem no cotidiano, assim, ao assistir em casa ou na televisão cenas de beijos, reproduzem nas brincadeiras situações semelhantes àquelas que vivenciaram.

O fato é que a "cabaninha de beijar" é apenas uma reprodução do cotidiano, trata-se de uma experiência não genitalizada, faz parte de um movimento exploratório da criança de conhecer o seu corpo e o corpo do outro. A criança traz consigo a marca da cultura, do meio social em que vive e, desde cedo, as características do desenvolvimento da sua sexualidade. À medida que a criança apresenta as primeiras manifestações de sexualidade, como, por exemplo, o toque, o brincar, o reconhecer o seu corpo e o corpo do outro, e o adulto reage a esses primeiros movimentos exploratórios de maneira nem sempre positiva, acaba-se por interpretar e atribuir a essas situações uma conotação que não condizem com realidade.

Vivemos alguns dilemas e contradições, de um lado há um conservadorismo, de outro os corpos de crianças e adolescentes são utilizados pelos meios de comunicação como vitrines de estímulo ao consumo. Assim, observamos a oferta de produtos como sutiã de bojo, a partir do tamanho de seis anos, calçados e roupas para crianças com características sensuais. Essa "hipersexualização" pode trazer danos psicológicos para algumas crianças. A afirmação é constada em estudo realizado por Zurbriggen (20I0), pela força-tarefa da American Psychological Association (APA), que apresenta algumas evidências dessa "hipersexualização" nas letras e vídeos de músicas, nos filmes, nas revistas, na mídia esportiva, em jogos de videogame, na internet e em propagandas.

Ao mesmo tempo em que são apresentados discursos de proteção, elas têm sido veículo de consumo. Há uma ideia da infância como objeto a ser apreciado, desejado, exaltado, em uma espécie de "pedofilização" generalizada da sociedade (FELIPE; GUIZZO, 2003). Nesse sentido, Landini (2000) afirma que ocorre uma "erótica infantil", isto é, uma erotização da imagem da criança amplamente veiculada pela mídia.

Felipe e Guizzo (2003) citam que as representações sobre sexualidade, corpo e gênero veiculadas pela mídia têm subjetivado não só os adultos, mas também têm trabalhado minuciosamente para a formação das identidades de crianças e de adolescentes nos dias de hoje. Xavier Filha (2009) afirma que os vários contextos educacionais presentes na sociedade, como cinema, mídia, revistas, 
brinquedos, entre outros, expressam e fazem circular discursos que produzem determinadas subjetividades.

Zurbriggen (2010) recomenda que urgentemente devemos ter uma atitude crítica frente às mídias, e ao consumo, em especial em relaçãoà "sexualização" das meninas e mulheres. Entre as recomendações está a inclusão de programas de educação em sexualidade e grupos para empoderar positivamente meninas e meninos enfatizando talentos, competências e habilidades mais importantes que a aparência física (ZURBRIGGEN, 20I0).

Constatamos que as professoras confundem o conceito de sexualidade. Ao investigar, percebemos que $o$ conceito de sexualidade que elas mencionam de maneira geral encontrava-se afastado do real significado da palavra. Sendo que sexo é definido como a diferença biológica entre homens e mulheres e a sexualidade, como algo que faz parte das dimensões do ser humano, que envolve um conjunto de regras socioculturais, emoções e sentimento, sendo essa última em nosso estudo reduzida à prática sexual (BRANDÃO; HEILBORN, 2006). Segundo Picazio (1999), corrigir a noção errônea de que sexualidade se resume ao ato sexual é extremamente relevante para compreender os aspectos que compõem a sexualidade e para entender as várias formas de manifestações sexuais.

\section{Considerações Finais}

Observamos que as principais dificuldades enfrentadas pelas professoras estão relacionadas ao desconhecimento de questões que envolvem o desenvolvimento de crianças e pré-adolescentes. O que, para os estudantes, são ações exploratórias em busca do conhecimento de si e do desenvolvimento da sexualidade, para as professoras são manifestações sexuais genitalizadas. $O$ fato de as professoras terem essa concepção é decorrente de construções sócio-históricas e de conhecimentos incipientes acerca do desenvolvimento humano.

Compreender o processo de desenvolvimento humano e a necessidade da educação em sexualidade não significa permitir a libertinagem, mas facilitar o contato sadio e protegido entre meninos e meninas no âmbito escolar. A sexualidade, quando adequadamente canalizada, se traduz em amor, autoconhecimento, criatividade, potência geradora de progresso e de desenvolvimento.

Outra constatação desse estudo é que a escola, enquanto instituição social e de ensino, é elemento quase ausente nos currículos universitários, seja pela escassa integração da universidade com a escola ou pelas lacunas da política nacional de formação docente.

Essa falta de integração entre os currículos de formação e a escola ocasionam um fazer pedagógico dissociado da realidade, resultando em fazeres que se perdem. Isso pode ser constatado pelo abismo entre a teoria estudada nas universidades e a prática junto a crianças e pré-adolescentes.

A pesquisa sinaliza que há questões importantes a serem incluídas na formação tanto inicial quanto continuada de professoras e professores. Um estudo mais aprofundado dessas questões os auxiliará significativamente em uma prática docente mais alinhada com as demandas da contemporaneidade.

Os dados apresentados confirmam que, na criança e no pré-adolescente, existe todo um universo da sexualidade, bem como comprovam que docentes que lidam com essa faixa etária não estão preparados para lidar com essa demanda.

O recorte apresentado nesse artigo permitiu que conhecêssemos a percepção e o conceito que as professoras atribuem à sexualidade no cotidiano escolar. A partir dos achados, foi possível compreender como se constroem as realidades, como um conhecimento adquire status de verdade e o quanto é complexa a desconstrução de paradigmas.

\section{Referências}

AUAD, D. Educar meninas e meninos: relações de gênero na escola. São Paulo: Contexto, 2006.

BADINTER, E. XY- De l'identité masculine. Paris: Odile Jacob, 1992.

BERNARDI, M. A deseducação sexual. São Paulo: Summus, 1985.

BOZON, M. Educação sexual dos jovens. In: BOZON, M. Sociologia da sexualidade. Rio de Janeiro: FGV Editora, 2004. p .66-67.

HENRIQUES, R. et al. (Org.). Gênero

e diversidade sexual na escola: reconhecer diferenças e superar preconceitos. Brasília: Secretaria de Educação Continuada, Alfabetização e Diversidade, 2007. (Cadernos SECAD, 4)

BRASIL. Lei $n^{\circ}$ 12.852, de 5 de agosto de 2013 . Estatuto da Juventude e dispõe sobre os direitos dos jovens, os princípios e diretrizes das políticas públicas de juventude e o Sistema Nacional de Juventude - SINAJUVE. Disponível em:< http://www.planalto.gov.br/ccivil_03/_Ato20I I20 I4/20 I3/Lei/LI 2852.htm > Acesso em: 24 out. 2018.

BRÊTAS, J. R. S. Principais conceitos. In: BRÊTAS, J. R. S. (Org.). Sexualidades. São Paulo: All Print, 201 I. p. 59-60. 
BRANDÃO, E. R.; HEILBORN, M. L. Sexualidade e gravidez na adolescência entre jovens de camadas médias do Rio de Janeiro, Brasil. Cadernos de Saúde Pública, Rio de Janeiro, v. 22, n. 7, p. I42I-I430, 2006.

CONNELL, R.W. Políticas da masculinidade: gênero e educação. Educação \& Realidade, Porto Alegre, v. 20, n. 2, p. 185-206, 1995.

\section{CONSELHO NACIONAL DE COMBATE}

À DISCRIMINAÇÃO (Brasil). Brasil sem homofobia: Programa de Combate à Violência e à Discriminação contra GLTB e de Promoção da Cidadania Homossexual. Brasília: SEDH, 2004.

CONSELHO NACIONAL DE SAÚDE (Brasil). Resolução n. 466/I 2. Diário Oficial da União, Brasília, n. 12, p. 59, 20।3. Seção I.

FELIPE, J. Erotização dos corpos infantis. In: LOURO, G. L.; FELIPE, J.; GOELLNER, S. V. Corpo, gênero e sexualidade: um debate contemporâneo da Educação. Rio de Janeiro:Vozes, 2010.

FELIPE, J.; GUIZZO, B. S. Erotização dos corpos infantis na sociedade de consumo. Pro-Posições, Campinas, v. I4, n. 3 p. II9-130, set./dez. 2003.

FINCO, D. A educação dos corpos femininos e masculinos na educação infantil. In: FARIA, A.L.G. (Org.). O coletivo infantil em creches e pré-escolas: falares e saberes. São Paulo: Cortez, 2007. p. 94-II9.

FREIRE, J. B. Educação de corpo inteiro: teoria e prática de Educação Física. Pedagogia do movimento na escola de primeira infância: um nome inadequado. São Paulo: Scipione, 20I I.

FURLANI, J. Educação sexual: possibilidades didáticas. In: LOURO, G. L.; FELIPE, J.; GOELLNER, S. V. Corpo, gênero e sexualidade: um debate contemporâneo da Educação. Petrópolis, RJ: Vozes, 20I0. p. 66-8I.

GATTI, B. A. Grupo focal na pesquisa em ciências sociais e humanas: série pesquisa em educação. Brasília: Liber livro, 2005.

GIL, A. C. Métodos e técnicas de pesquisa social. São Paulo: Atlas, 2006.

HENRIQUES, F.; Elisabeth, Badinter: racionalismo, igualdade e feminismo. In:
CONGRESSO EVOCATIVO DO PRIMEIRO CONGRESSO FEMINISTA EM PORTUGAL. Lisboa. Universidade de Èvora. 2005.

p. I-9. Disponível em:< http://evunix. uevora.pt/ $\sim$ fhenriques/textos-filegenero/ elisabetebadinter.pdf > Acesso em: 22 jul. 2015.

HEILBORN, M. L.; ROHDEN, F. Gênero e diversidade na Escola: a ampliação do debate. In: PEREIRA, M. E. Gênero e diversidade na escola: formação de professoras/es em gênero, orientação sexual e relações étnico-raciais. Rio de Janeiro: CEPESC; Brasília. SPM, 2009. p. II-I2.

KITZINGER, J. Grupos focais. In: POPE, C.; MAYS, N. (Org.). Pesquisa qualitativa na atenção à saúde. Porto Alegre: Artmed, 2009. p. 33-4l.

LANDINI, T. S. Pornografia infantil na internet: proliferação e visibilidade. Dissertação (Mestrado em Sociologia da FFLCH-USP) - Faculdade de Filosofia, Letras e Ciências Humanas, Universidade de São Paulo, São Paulo, 2000.

LOURO, G. L. Pedagogias da sexualidade. In: LOURO, G. L. (Org.). O corpo educado: pedagogias da sexualidade. Belo Horizonte: Autêntica, 200I p. 6-8.

MELLO, L.; AVELAR, R. B.; MAROJA, D. Por onde andam as políticas públicas para a população LGBT no Brasil. Sociedade e Estado, v. 27, n. 2 p. $289-3 / 2,2012$.

MILLOT, C. É possível uma pedagogia analítica? In: MILLOT, C. Freud antipedagogo. Rio de Janeiro: Zahar, 1987. p. I52-I53.

MINAYO, M. C. S. O desafio do conhecimento: pesquisa qualitativa em saúde. São Paulo: Hucitec, 2010.

ORGANIZAÇÃO MUNDIAL DA SAÚDE. Gender and reproductive rights - Working definitions. Disponível em: < http://www.who. int/reproductivehealth/topics/sexual_health/sh_ definitions/en/ > Acesso em: 22 jul.20l5.

PICAZIO, C. O sexo secreto: temas polêmicos da sexualidade. São Paulo: Editora GLS, 1999. 
PRINCÍPIOS DE YOGYAKARTA. Princípios sobre a aplicação da legislação internacional de direitos humanos em relação à orientação sexual e identidade de gênero. 2007. Disponível em: < http://yogyakartaprinciples.org/principles-sp/ > Acesso em: 22 jul.20I5.

PROENÇA, M. A. R. A rotina como âncora do cotidiano na educação infantil. Revista Pátio Educação Infantil, Porto Alegre, v. 2, n. 4 p. I3-15, 2004.

UNBEHAUM, S.; CAVASIN, S.; GAVA, T. Gênero e sexualidade nos currículos de pedagogia - fazendo gênero, diásporas, diversidades, deslocamentos. In: FAZENDO GÊNERO, 9., 2010. Florianópolis. Anais... Florianópolis: Universidade Federal de Santa Catarina, 2010. p. I-I0. Disponível em: http:// www.fazendogenero.ufsc.br/9/resources/ anais/I 278 I 7 I I00_ARQUIVO_Gen_Sex_Curric Ped_STI9_FG9.pdf > Acesso em: 24 jul. 2015.

UNBEHAUM, S.; CAVASIN, S. As políticas de Educação em Sexualidade no Brasil - 2003 a 2008. 2012. Disponível em: < https://docplayer.com. $\mathrm{br} / 19264785$-As-politicas-de-educacao-emsexualidade-no-brasil-2003-a-2008.html > Acesso em: 24 jul. 20 I5.

UNESCO. Orientações técnicas de educação em sexualidade para o cenário brasileiro: tópicos e objetivos de aprendizagem. Brasília: UNESCO, 2014.

XAVIER FILHA, C. Sexualidade (s) e gênero (s) em artefatos culturais para a infância: práticas discursivas e construção de identidades. In: XAVIER FILHA, C. (Org.). Educação para a sexualidade, para a equidade de gênero e para a diversidade sexual. Campo Grande, MS: Editora da UFMS, 2009.

ZURBRIGGEN, E. L. Report of the APA Task Force on the Sexualization of Girls: Executive Summary. Washington, DC, 20I0. Disponível em: < http:// www.apa.org/pi/women/programs/girls/report. aspx>. Acesso em: 27 jul. 2015. 